\title{
Kaempferol induces cell cycle arrest and apoptosis in renal cell carcinoma through EGFR/p38 signaling
}

\author{
WENBIN SONG $^{1 *}$, QIANG DANG ${ }^{1 *}$, DEFENG XU ${ }^{2}$, YULE CHEN $^{1}$, GUODONG ZHU $^{1}$, \\ KAIJIE WU ${ }^{1}$, JIN ZENG ${ }^{1}$, QINGZHI LONG ${ }^{1}$, XINYANG WANG ${ }^{1}$, DALIN HE ${ }^{1}$ and LEI LI ${ }^{1}$ \\ ${ }^{1}$ Department of Urology, The First Affiliated Hospital of the Medical College of \\ Xi'an Jiaotong University, Xi'an, Shaanxi 710061; ${ }^{2}$ School of Pharmaceutical and Life Sciences, \\ Changzhou University, Changzhou, Jiangsu 213164, P.R. China
}

Received October 16, 2013; Accepted December 2, 2013

DOI: $10.3892 / o r .2014 .2965$

\begin{abstract}
Kaempferol has been shown to inhibit cell growth, induce apoptosis and cell cycle arrest in several tumors, but not in renal cell carcinoma (RCC). In the present study, we investigated the effects of kaempferol and the underlying mechanism(s) on the cell growth of RCC cells. MTT assay and colony formation assay were used to study cell growth, and flow cytometry was used to study apoptosis and cell cycles in different RCC cells treated with various doses of kaempferol. A significant inhibition on cell growth, induction of apoptosis and cell cycle arrest were observed in 786-O and 769-P cells after kaempferol treatment compared with the control group. Moreover, the results clearly showed that kaempferol causes a strong inhibition of the activation of the EGFR/p38 signaling pathways, upregulation of p21 expression and downregulation of cyclin B1 expression in human RCC cells, together with activation of PARP cleavages, induction of apoptotic death and inhibition of cell growth. Collectively, our results suggest that kaempferol may serve as a candidate for chemopreventive or chemotherapeutic agents for RCC.
\end{abstract}

\section{Introduction}

Renal cell carcinoma ( $\mathrm{RCC}$ ) is one of the most commonly diagnosed urological malignancies in China. Although surgery is the main therapy for RCC, some patients are already considered to have metastatic RCC (mRCC) at time of diagnosis (1). For those particular patients, the treatment relies mainly on systemic therapy including chemotherapy, radiation therapy

Correspondence to: Dr Dalin He or Dr Lei Li, Department of Urology, The First Affiliated Hospital of the Medical College of Xi'an Jiaotong University, Xi'an, Shaanxi 710061, P.R. China

E-mail: dalinhexjtu@126.com

E-mail: lilydr@163.com

*Contributed equally

Key words: kaempferol, renal cell carcinoma, cell growth, cell cycle, epidermal growth factor receptor/p38 and immune therapy, but their effects are limited $(1,2)$. RCC expresses multidrug resistance transporters and is refractory to chemotherapy once it becomes metastatic (3). With this concern, novel agents are being developed to target mRCC; one approach to control RCC is growth inhibition wherein the disease is prevented, slowed by the administration of one or more non-toxic naturally occurring or synthetic agents (4).

Kaempferol, a flavonoid, is a yellow compound with a low molecular weight (MW:286.2 g/mol) (5). Kaempferol has been identified in many botanical families, and several epidemiological studies have evaluated the possible association between the consumption of foods containing kaempferol and a reduced risk of developing several disorders (6-8). For anticancer activity, kaempferol induced apoptosis in ovarian cancer (9), oral cavity cancer (10), osteosarcoma (11) and colon cancer (12). Kaempferol was also able to inhibit cell growth (13) and angiogenesis $(14,15)$, which is necessary for solid tumor formation.

Epidermal growth factor receptor (EGFR) is one of the members of the ErbB receptor tyrosine kinase family and plays a critical role in a wide variety of cellular functions, including proliferation, differentiation and apoptosis (16). Several studies have shown that EGFR and other members of their family together with the growth factors that activate them are overexpressed in RCC tissue and cell lines (17,18). Mitogen-activated protein kinases (MAPKs) are serine/threonine-specific protein kinases. p38 is one of the MAPKs, and could regulate cell proliferation. EGFR could mediate p38 activation (19). In this study, we found kaempferol could functions mainly through the EGFR/p38 pathway to inhibit RCC cell growth.

\section{Materials and methods}

Cell culture. Human RCC cell lines (786-O and 769-P) were purchased from ATCC and were maintained in RPMI-1640 containing $10 \%$ fetal bovine serum (FBS), 2 mM L-glutamine, $100 \mathrm{IU} / \mathrm{ml}$ penicillin, $50 \mu \mathrm{g} / \mathrm{ml}$ streptomycin. All cells were cultured at $37^{\circ} \mathrm{C}$, in a humidified atmosphere containing $5 \% \mathrm{CO}_{2}$.

Reagents. Kaempferol was a gift from Dr Defeng $\mathrm{Xu}$ of Changzhou University; it was dissolved in DMSO at $50 \mathrm{mM}$ and stored at $-20^{\circ} \mathrm{C}$. Antibodies against human Chk1, CDK2, 
p35, c-jun, cyclin B1 and GAPDH were purchased from Santa Cruz Biotechnology, Inc. Antibodies against p-EGFR, EGF, p-MEK, MEK and p-p38 were purchased from Cell Signaling Technology, Inc. AG1478 was from Calbiochem and SB203580 was purchased from Cell Signaling Technology, Inc. Annexin V-FITC Apoptosis Detection kit was from Nanjing Jiancheng Bioengineering Institute.

Cell viability. Cell viability was assessed using a tetrazoliumbased assay (MTT assay). One thousand cells in $50 \mu \mathrm{l}$ of media per well were plated in 96-well plates. Cells treated with or without different doses of kaempferol were incubated for various times, and then incubated with $0.5 \mathrm{mg} / \mathrm{ml}$ of MTT at $37^{\circ} \mathrm{C}$ for $1 \mathrm{~h}$. Subsequently, the supernatant was dropped and dissolved with DMSO. Colorimetric analysis using a 96-well microplate reader was performed at the wavelength of $490 \mathrm{~nm}$. The experiments were performed in triplicate.

Colony formation assay. RCC cells (786-O and 769-P) were respectively seeded in 24 -well plates (100 cells/well) and cultured with different doses of kaempferol (50, 100 and $150 \mu \mathrm{M}$ ) for 14 days before staining. The colonies were stained with crystal violet and counted.

Quantitative detection of apoptosis. Cells (786-O and 769-P) were exposed to different doses of kaempferol (50, 100 and $150 \mu \mathrm{M}$ ) for $48 \mathrm{~h}$. The cells were collected and subjected to Annexin $\mathrm{V}$ and propidium iodide (PI) staining using an Annexin V-FITC Apoptosis Detection kit, following the protocol provided by the manufacturer. Apoptotic cells were then analyzed by flow cytometry.

Cell cycle detection assay. After cells reached 60-80\% confluence, they were treated with different doses of kaempferol $(50,100$ and $150 \mu \mathrm{M})$. After $48 \mathrm{~h}$, cells were washed twice with PBS and fixed with $70 \%$ ethanol for $1 \mathrm{~h}$ at $4^{\circ} \mathrm{C}$, and then washed with PBS and resuspended with PI solution $(0.05 \mathrm{mg} / \mathrm{ml})$ containing RNase, and incubated at room temperature in the dark for $30 \mathrm{~min}$. DNA content was then analyzed using the flow cytometer.

Western blot analysis. Cells were lysed in RIPA buffer $(50 \mathrm{mM}$ Tris-HCl/pH 7.4, 1\% NP-40, 150 mM NaCl, 1 mM EDTA, 1 mM PMSF, $1 \mathrm{mM} \mathrm{Na} \mathrm{VO}_{4}, 1 \mathrm{mM} \mathrm{NaF}, 1 \mathrm{mM}$ okadaic acid, and $1 \mathrm{mg}$ / $\mathrm{ml}$ aprotinin, leupeptin, and pepstatin) with Protease Inhibitor Cocktail (Roche Inc.). Individual samples (25 $\mu$ g protein) were prepared for electrophoresis run on 12-15\% SDS-PAGE gel and then transferred onto PVDF membranes (Millipore). After blocking the membranes with 5\% BSA in PBS for $1 \mathrm{~h}$ at room temperature, the membranes were incubated with appropriate dilutions of specific primary antibodies overnight at $4^{\circ} \mathrm{C}$. After washing, the blots were incubated with anti-rabbit, anti-mouse or anti-goat IgG HRPs for $1 \mathrm{~h}$. The blots were developed in ECL mixture (Thermo Fisher Scientific Inc.).

Statistical analyses. All statistical analyses were performed using SPSS 16.0. Quantitative data are presented as mean \pm SE and the differences among various treatment groups were compared by one-way ANOVA, followed by Dunnett's t-test for separate comparisons. When the comparison involved only
A<smiles>O=c1c(O)c(-c2ccc(O)cc2)oc2cc(O)cc(O)c12</smiles>

B

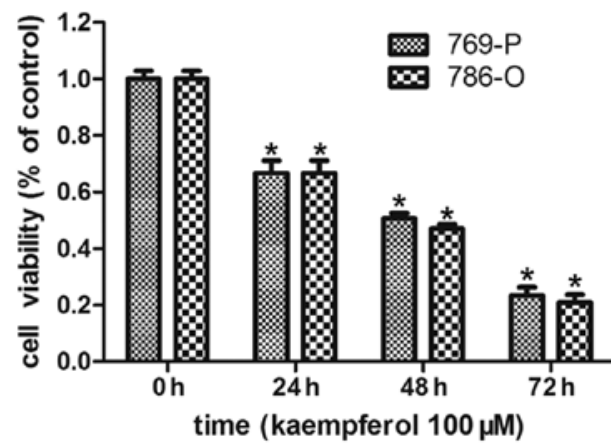

C

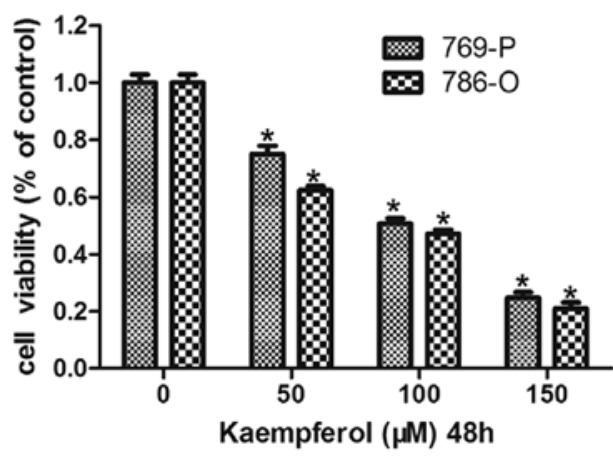

Figure 1. The effect of kaempferol on RCC cell growth. (A) The chemical structure of kaempferol. (B) RCC (786-O and 769-P) cells were treated with $100 \mu \mathrm{M}$ kaempferol for different time periods ( $0,24,48$, and $72 \mathrm{~h})$. (C) RCC (786-O and 769-P) cells were treated with the indicated doses of kaempferol $(50,100$ and $150 \mu \mathrm{M})$ for $48 \mathrm{~h}$. Cell viabilities were detected by MTT assay. ${ }^{*} \mathrm{P}<0.05$ was considered to indicate a statistically significant difference.

2 groups, Student's t-test was used. $\mathrm{P}<0.05$ was considered to indicate statistically significant differences.

\section{Results}

Kaempferol inhibits cell growth and induces cell death in RCC cells. First, we demonstrated the effect of kaempferol (structure shown in Fig. 1A) on the growth of RCC cells (786-O and 769-P), as shown in Fig. 1. Kaempferol treatment inhibited the growth of 786-O and 769-P cells in both a dose- and a timedependent manner. We fixed its concentration at $100 \mu \mathrm{M}$ and treated RCC cells for 24, 48 and $72 \mathrm{~h}$, resulting in $\sim 78,50$ and $30 \%$ cell survival respectively (Fig. 1B), and then kaempferol treatment at 50,100 and $150 \mu \mathrm{M}$ doses resulted in the same tendency decreasing cell survival.

Kaempferol inhibits colony formation of RCC cells. We also tested the effect of kaempferol on colony formation, which is another type of proliferation assay. One hundred of each RCC cell type (786-O and 769-P) were seeded into 24-well plates, 
A

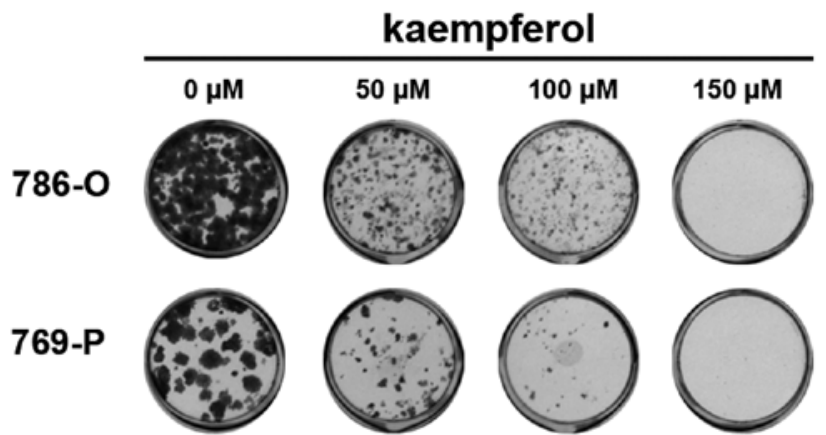

B

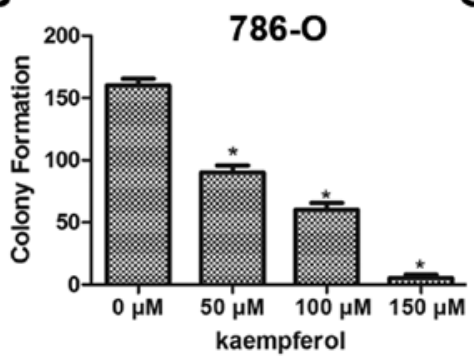

C

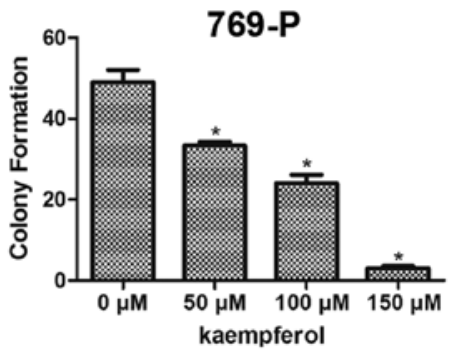

Figure 2. Kaempferol inhibits colony formation of RCC cells. (A) Colony formation assay (24-well). One hundred cells of 786-O or 769-P were seeded into 24-well plates and cultured with kaempferol at different doses $(50,100$ and $150 \mu \mathrm{M})$ for 14 days. They were then stained with crystal violet and colony numbers were counted. (B and $\mathrm{C}$ ) The quantification for colony formation. ${ }^{*} \mathrm{P}<0.05$ was considered to indicate a statistically significant difference.

A

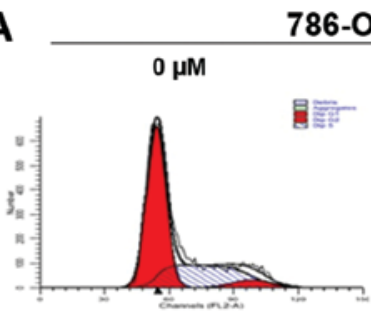

786-0 kaempferol

$100 \mu \mathrm{M}$

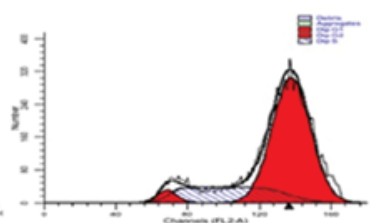

B

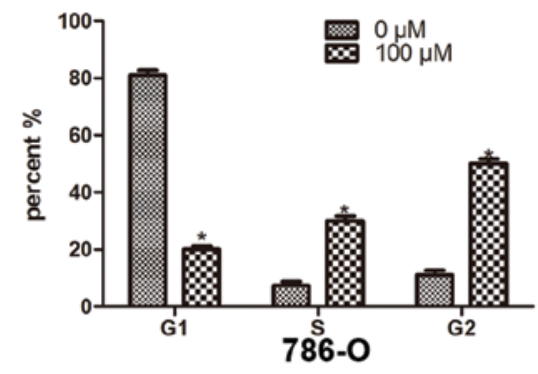

C

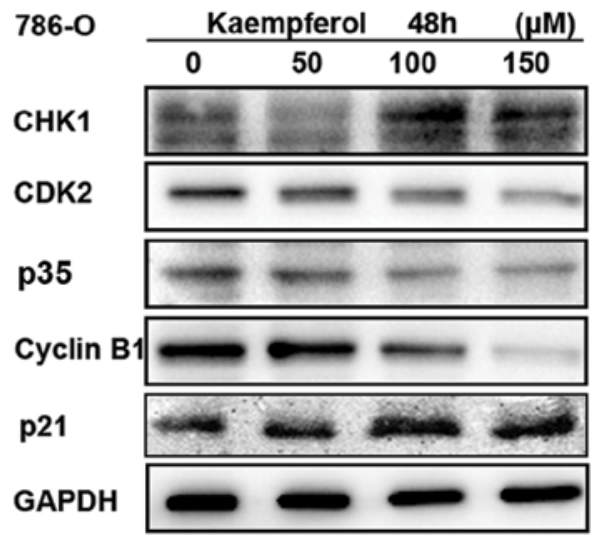

769-P kaempferol
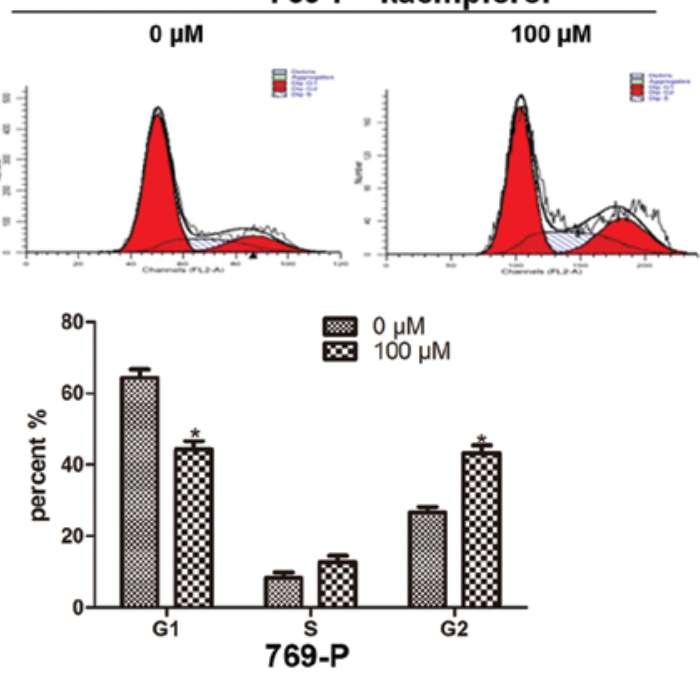

769P

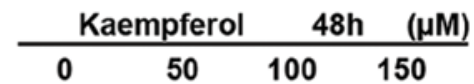

CHK1

CDK2

p35

Cyclin B1

p21

GAPDH
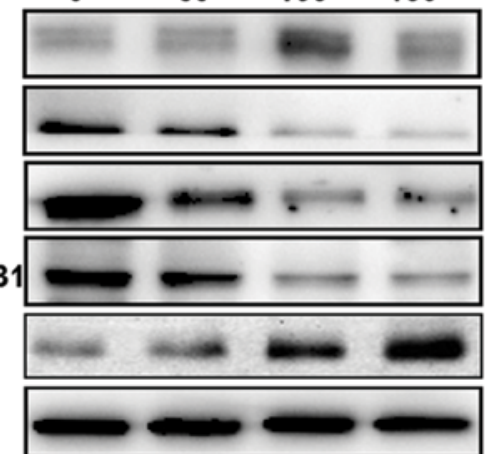

Figure 3. Kaempferol induces RCC cell cycle arrest. (A) Cell cycle analyses. After treating with the indicated doses of kaempferol, cells were collected fixed, and stained with PI, and then DNA contents were analyzed by FACS. (B) The quantification of cell percentage for each cell stage. (C) Cell lysates from 786-O and 769-P were analyzed to detect CHK1, CDK2, p35, cyclin B1 and p21. GAPDH was used as loading control. ${ }^{*} \mathrm{P}<0.05$ was considered to indicate a statistically significant difference. 
A

kaempferol
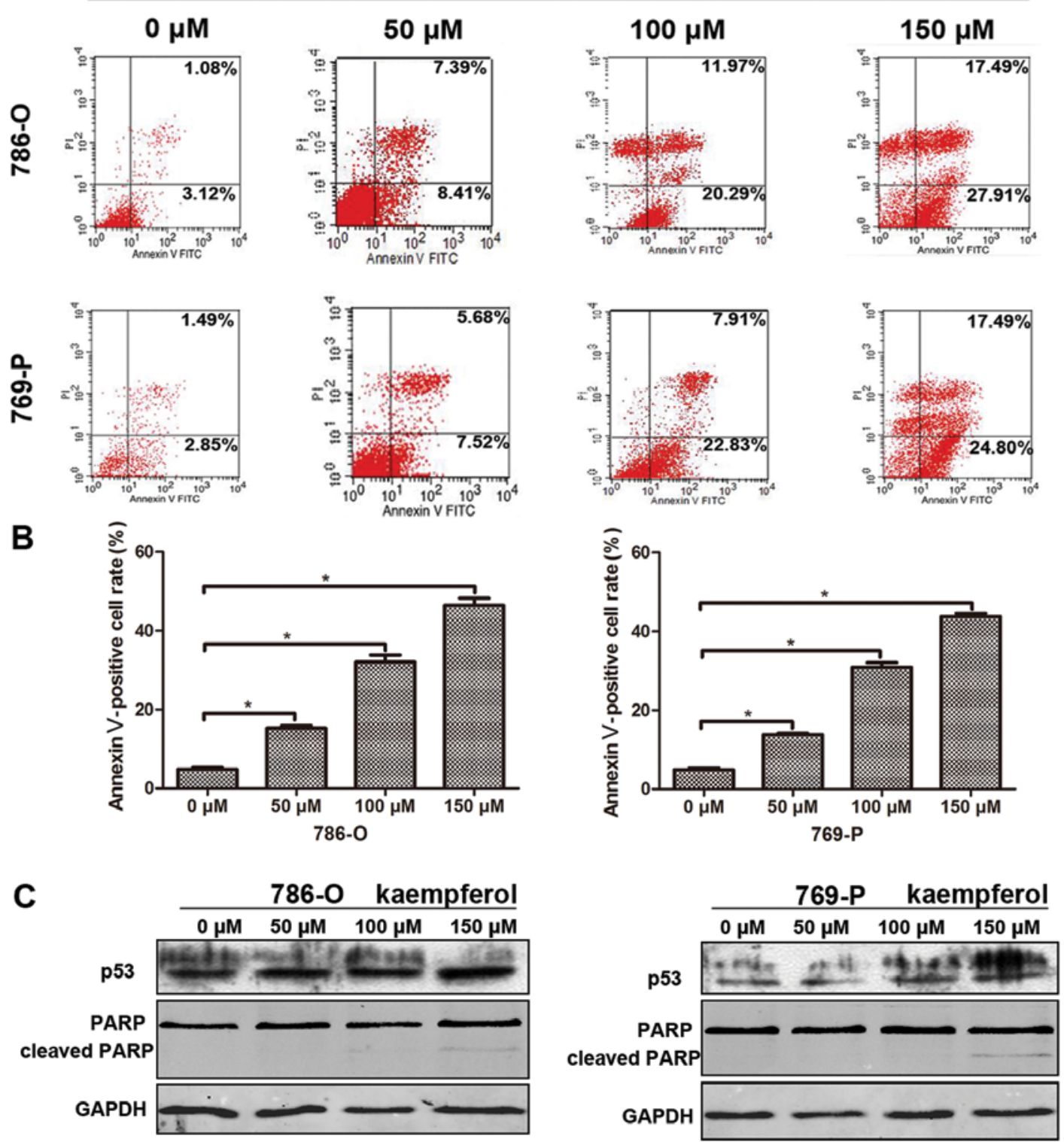

Figure 4. Kaempferol induces RCC cell apoptosis. (A) After treating with the indicated doses of kaempferol (50, 100 and $150 \mu \mathrm{M}$ ) for $48 \mathrm{~h}, 786-\mathrm{O}$ and $769-\mathrm{P}$ cells were collected and stained with Annexin V and PI, and then analyzed by FACS. (B) The quantification for Annexin V positive cells. (C) After similar treatment, total lysates were analyzed to detect $\mathrm{p} 53(1: 1,000)$ and cleaved PARP $(1: 1,000)$ by western blotting. ${ }^{*} \mathrm{P}<0.05$ was considered to indicate a statistically significant difference.

and cultured with kaempferol at 50, 100 and $150 \mu \mathrm{M}$ doses for 14 days. As shown in Fig. 2, it is evident that kaempferol significantly inhibited colony formation of both 786-O (Fig. 2B) and 769-P (Fig. 2C) cells.

Kaempferol induces cell cycle arrest in RCC cells. We further detected the effect of kaempferol on cell cycle arrest by flow cytometry. After kaempferol treatment for $24 \mathrm{~h}$ at $100 \mu \mathrm{M}$, most cells arrested mainly at phase G2-M stage $52.36 \%$ in $786-\mathrm{O}$ cell and $43.45 \%$ in $769-\mathrm{P}$ cells (Fig. 3A and B). Consistently, we observed that several cell cycle related gene expressions were altered, for example, Chk1 and p21waf1/Cip1 increased, while CDK2, p35 and cyclin B1 decreased in 786-O and 769-P cells after treatment for $48 \mathrm{~h}$ with different doses of kaempferol (Fig. 3C). The results of Fig. 3A-C show that kaempferol induced cell cycle arrest.

Kaempferol induces RCC cell apoptosis. We also investigated the effects of kaempferol on apoptosis in 786-O and 769-P cells after they were treated with kaempferol for $48 \mathrm{~h}$ at 50, 100 and $150 \mu \mathrm{M}$. The flow cytometry data (Fig. 4A) showed Annexin V positive cells increased after treatment with kaempferol and there are significant differences compared with the control group, with Annexin V positive cells increased to 15.8, 32.26 and $45.4 \%$ in $786-\mathrm{O}$ cells, and $13.2,30.74$ and $42.29 \%$ in $769-\mathrm{P}$ cells (Fig. 4B). Next, we used western blotting to detect apoptosis related gene expression, and we found p53 and cleaved PARP increased after treatment with kaempferol (Fig. 4C). 
A
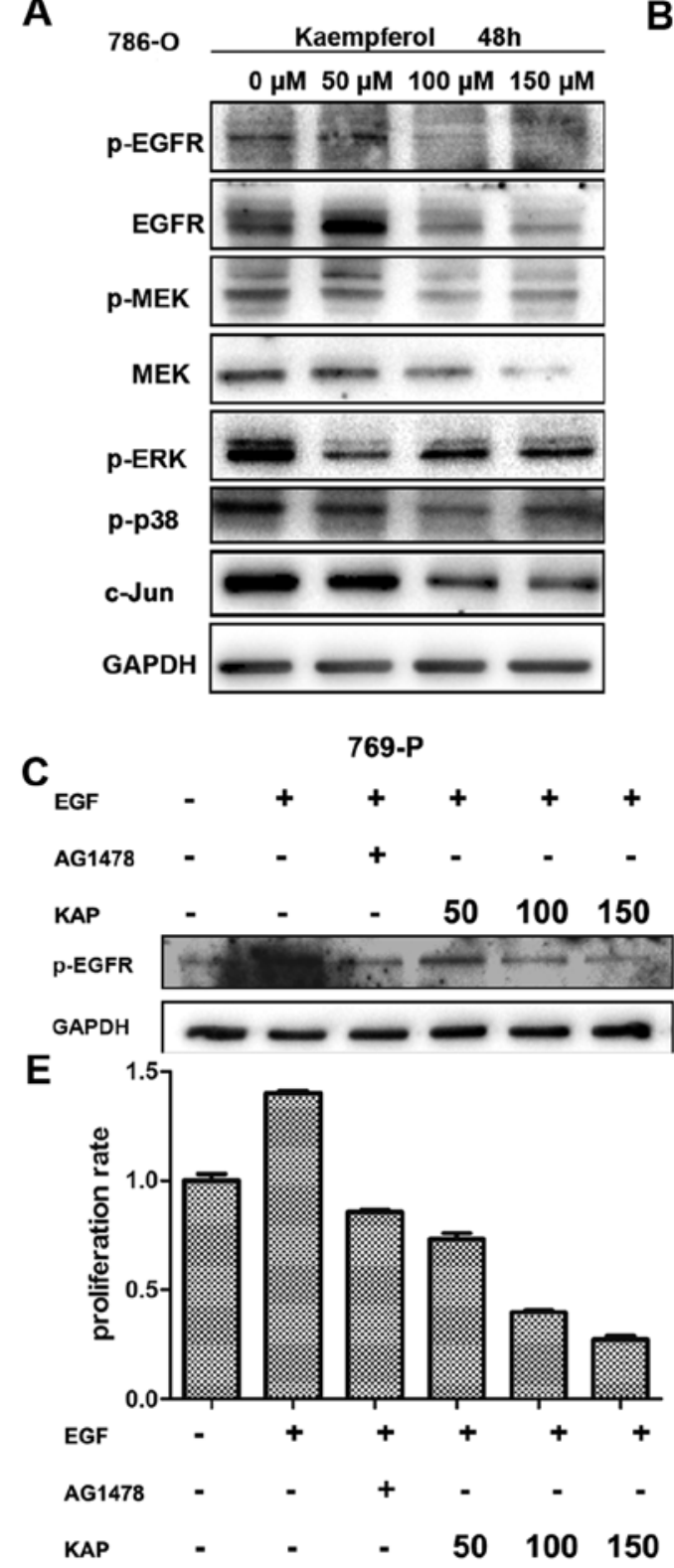

B

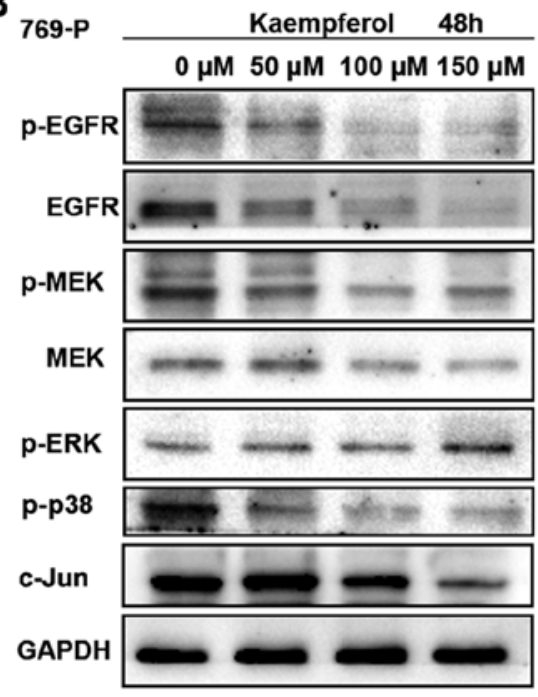

D

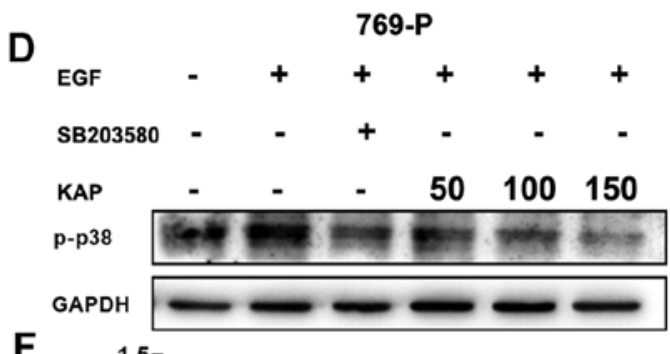

$\mathbf{F}$

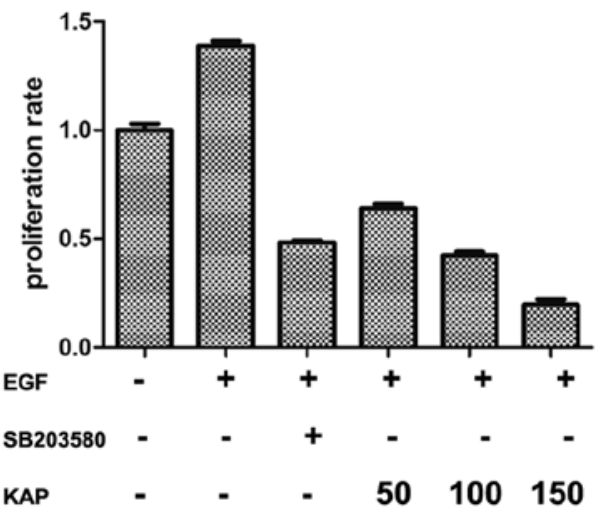

Figure 5. Kaempferol goes through the EGFR/p38 MAPK signaling pathway to inhibit cell growth. (A and B) 786-O or 769-P cells lysates were analyzed to detect p-EGFR, EGFR, p-MEK, MEK, p-p38, p-ERK and c-jun by western blotting. GAPDH was used as a loading control. (C and D) 786-O cells were treated with AG1478 (EGFR inhibitor) or SB203580 (p38 inhibitor) and different doses of kaempferol for $48 \mathrm{~h}$; before cell collection, cells were treated with EGF for 30 min to activate p-EGFR or phospho-p38, and then p-EGFR or phospho-p38 expression was detected by western blotting. (E and F) Cells were seeded in 24-well plates, treated with AG1478 or SB203580 and kaempferol for $2 \mathrm{~h}$. EGF was added for $48 \mathrm{~h}$, and then MTT assay was applied to detect cell proliferation.

Kaempferol inhibits cell growth through the EGFR/p38 MAPK signaling pathway. Since we showed that kaempferol inhibits cell proliferation, the underlying mechanisms were then further investigated. We screened the expression of some growth related genes, and binding kaempferol significantly inhibited the activation of the EGFR pathway, as shown in Fig. 5A and B, EGFR and phospho-EGFR, MEK and phosphoMEK, phospho-p38 and its downstream c-jun, decreased after treatment with kaempferol. However, we also found that the expression of ERK increased, which may be related to stress, since we know kaempferol induces (endoplasmic reticulum) stress.

As is well known, EGFR goes through the MAPK pathway to influence cell proliferation (20). To delineate the growth inhibition of RCC cells upon kaempferol treatment was mainly through the EGFR/MAPK signaling pathway, we used EGFR inhibitor AG1478 (21) and p38 inhibitor SB203580 (22) to study their effects on cell growth. First, as shown in Fig. 5C and D, kaempferol blocked EGF induced p-EGFR and activation of $\mathrm{p} 38$, similar to their inhibitors. This indicated that kaempferol blocked the EGFR/p38 signaling pathway.

We used the MTT assay to detect cell viability of 786-O and 769-P after treatment with EGR as well as EGFR inhibitor AG1478, or p38 inhibitor SB203580 and kaempferol for $48 \mathrm{~h}$, as shown in Fig. 5E and F. Kaempferol significantly inhibited cell growth simulated EGFR inhibitor or p38 inhibitor. Collectively, we suggest kaempferol inhibited cell growth via the EGFR/p38 signaling pathway. 


\section{Discussion}

Kaempferol has been reported to inhibit the cell growth of several types of cancer and to induce apoptosis. However, in $\mathrm{RCC}$, the effect of kaempferol remains unclear. This study is the first to demonstrate that kaempferol inhibits RCC cell line growth in vitro.

As our results show, kaempferol inhibited the cell growth of two different RCC cell lines, 786-O and 769-P. In previous studies, kaempferol was shown to inhibit prostate cancer cell (13), hepatocyte (23) and lung cancer cell (24) growth. This suggests kaempferol has a wide anti-proliferation capacity. In addition, our data showed $50 \mu \mathrm{M}$ kaempferol has an effect on cell growth, which is $\mu \mathrm{M}$ grade and a relatively low concentration, suggesting it has a low toxicity and is relatively safe; however, in vivo studies to test and verify this are required.

Cell cycle progression is tightly controlled by a subfamily of cyclin-dependent kinases (CDKs), the activity of which is regulated by several activators (cyclins) and cyclin-dependent kinase inhibitors (CDKIs) (25). In several other types of cancer, kaempferol was demonstrated to cause G2/M phase arrest (26-29), but in our results we also observed G1/S phase arrest in RCC cell lines, which is associated with p21waf1/cip1 upregulation in RCC cells. Kaempferol could induce DNA damage, increase ATM, and lead to $\mathrm{CHK} 1 / 2$ activation, which has several effector substrates, including cyclin B1.

An aberrant activation of several growth signaling pathways and evasion of apoptosis have been recognized as hallmarks of cancer cell survival and growth including RCC $(30,31)$ cells and the inhibition of growth mediated by blocking the EGFR/p38 pathway. We screened some growth related genes and found phospho-p38 and its downstream c-jun was downregulated, but, notably, phospho-ERK increased after treatment with kaempferol in our study, which may mediate cell apoptosis (24) or may be related to cell stress related with ER stress (32). Huang et al have already found that kaempferol could induce ER stress in osteosarcoma cells (11), and ERK acts as a stress consequence. Next, we detected some candidates upstream of p38, such as c-Met (20), and EGFR (33), which could lead to DNA synthesis and cell proliferation. Therefore, we suggest that kaempferol may function through the EGFR/p38 signaling pathway to inhibit cell growth. We utilized EGFR inhibitor AG1478 and p38 inhibitor SB203580 to confirm whether kaempferol has the same effects with inhibitors. Our results support the hypothesis that the EGFR/p38 signaling pathway is involved in growth inhibition by kaempferol in RCC.

In conclusion, the present study showed that kaempferol causes a strong inhibition of the activation of EGFR/p38 signaling pathways, upregulation of $\mathrm{p} 21$ expression, and downregulation of cyclin $\mathrm{B} 1$ expression in human RCC cells together with activation of PARP cleavages, induction of apoptotic death, and inhibition of cell growth. Further studies are required to establish the efficacy of kaempferol in pre-clinical RCC models, which may be useful in supporting a rationale for a clinical trial in RCC patients.

\section{References}

1. Cohen HT and McGovern FJ: Renal-cell carcinoma. N Engl J Med 353: 2477-2490, 2005.
2. Yagoda A, Abi-Rached B and Petrylak D: Chemotherapy for advanced renal-cell carcinoma: 1983-1993. Semin Oncol 22: 42-60, 1995.

3. Li L, Gao Y, Zhang L, Zeng J, He D and Sun Y: Silibinin inhibits cell growth and induces apoptosis by caspase activation, downregulating survivin and blocking EGFR-ERK activation in renal cell carcinoma. Cancer Lett 272: 61-69, 2008.

4. Bex A, Kerst M, Mallo H, Meinhardt W, Horenblas S and de Gast GC: Interferon alpha $2 b$ as medical selection for nephrectomy in patients with synchronous metastatic renal cell carcinoma: a consecutive study. Eur Urol 49: 76-81, 2006.

5. Calderón-Montaño JM, Burgos-Morón E, Pérez-Guerrero C and López-Lázaro M: A review on the dietary flavonoid kaempferol. Mini Rev Med Chem 11: 298-344, 2011.

6. Cui Y, Morgenstern H, Greenland S, et al: Dietary flavonoid intake and lung cancer - a population-based case-control study. Cancer 112: 2241-2248, 2008.

7. Nothlings U, Murphy SP, Wilkens LR, Henderson BE and Kolonel LN: Flavonols and pancreatic cancer risk: the multiethnic cohort study. Am J Epidemiol 166: 924-931, 2007.

8. Gates MA, Tworoger SS, Hecht JL, De Vivo I, Rosner B and Hankinson SE: A prospective study of dietary flavonoid intake and incidence of epithelial ovarian cancer. Int J Cancer 121: 2225-2232, 2007.

9. Luo H, Daddysman MK, Rankin GO, Jiang BH and Chen YC: Kaempferol enhances cisplatin's effect on ovarian cancer cells through promoting apoptosis caused by down regulation of cMyc. Cancer Cell Int 10: 16, 2010.

10. Kang JW, Kim JH, Song K, Kim SH, Yoon JH and Kim KS: Kaempferol and Kaempferol and quercetin, components of Ginkgo biloba extract (EGb 761), induce caspase-3-dependent apoptosis in oral cavity cancer cells. Phytother Res 24 (Suppl 1): S77-S82, 2010.

11. Huang WW, Chiu YJ, Fan MJ, et al: Kaempferol induced apoptosis via endoplasmic reticulum stress and mitochondriadependent pathway in human osteosarcoma U-2 OS cells. Mol Nutr Food Res 54: 1585-1595, 2010.

12. Li W, Du B, Wang T, Wang S and Zhang J: Kaempferol induces apoptosis in human HCT116 colon cancer cells via the AtaxiaTelangiectasia Mutated-p53 pathway with the involvement of p53 Upregulated Modulator of Apoptosis. Chem Biol Interact 177: 121-127, 2009.

13. Qin W, Lei Y-H, Su M, Li D-J, Zhang N and Shen Y-Q: Kaempferol inhibits proliferation of human prostate cancer PC-3 cells via down-regulation of PCNA and VCAM-1. Zhongguo Yaolixue Tongbao 27: 553-557, 2011 (In Chinese).

14. Ahn MR, Kunimasa K, Kumazawa S, et al: Correlation between antiangiogenic activity and antioxidant activity of various components from propolis. Mol Nutr Food Res 53: 643-651, 2009.

15. Schindler R and Mentlein R: Flavonoids and vitamin E reduce the release of the angiogenic peptide vascular endothelial growth factor from human tumor cells. J Nutr 136: 1477-1482, 2006.

16. Shin MS, Shinghirunnusorn P, Sugishima Y, et al: Cross interference with TNF-alpha-induced TAK1 activation via EGFR-mediated $\mathrm{p} 38$ phosphorylation of TAK1-binding protein 1. Biochim Biophys Acta 1793: 1156-1164, 2009.

17. Cohen D, Lane B, Jin T, et al: The prognostic significance of epidermal growth factor receptor expression in clear-cell renal cell carcinoma: a call for standardized methods for immunohistochemical evaluation. Clin Genitourin Cancer 5: 264-270, 2007.

18. Badalian G, Derecskei K, Szendroi A, Szendroi M and Timar J: EGFR and VEGFR2 protein expressions in bone metastases of clear cell renal cancer. Anticancer Res 27: 889-894, 2007.

19. Fanger GR, Johnson NL and Johnson GL: MEK kinases are regulated by EGF and selectively interact with $\mathrm{Rac} / \mathrm{Cdc} 42$. EMBO J 16: 4961-4972, 1997.

20. Marshall CJ: Specificity of receptor tyrosine kinase signaling: transient versus sustained extracellular signal-regulated kinase activation. Cell 80: 179-185, 1995.

21. Han Y, Caday CG, Nanda A, Cavenee WK and Huang HJ: Tyrphostin AG 1478 preferentially inhibits human glioma cells expressing truncated rather than wild-type epidermal growth factor receptors. Cancer Res 56: 3859-3861, 1996.

22. Clerk A and Sugden PH: The p38-MAPK inhibitor, SB203580, inhibits cardiac stress-activated protein kinases/c-Jun N-terminal kinases (SAPKs/JNKs). FEBS Lett 426: 93-96, 1998.

23. Labbe D, Provencal M, Lamy S, Boivin D, Gingras D and Beliveau R: The flavonols quercetin, kaempferol, and myricetin inhibit hepatocyte growth factor-induced medulloblastoma cell migration. J Nutr 139: 646-652, 2009. 
24. Nguyen TTT, Tran E, Ong CK, et al: Kaempferol-induced growth inhibition and apoptosis in A549 lung cancer cells is mediated by activation of MEK-MAPK. J Cell Physiol 197: 110-121, 2003.

25. Malumbres $M$ and Barbacid M: Cell cycle, CDKs and cancer: a changing paradigm. Nat Rev Cancer 9: 153-166, 2009.

26. Huang WW, Tsai SC, Peng SF, et al: Kaempferol induces autophagy through AMPK and AKT signaling molecules and causes $\mathrm{G}_{2} / \mathrm{M}$ arrest via downregulation of CDK1/cyclin B in SK-HEP-1 human hepatic cancer cells. Int J Oncol 42: 2069-2077, 2013.

27. Naowaratwattana W, De-Eknamkul W and De Mejia EG: Phenolic-containing organic extracts of mulberry (Morus alba L.) leaves inhibit HepG2 hepatoma cells through G2/M phase arrest, induction of apoptosis, and inhibition of topoisomerase II $\alpha$ activity. J Med Food 13: 1045-1056, 2010.

28. Zhang Q, Zhao XH and Wang ZJ: Cytotoxicity of flavones and flavonols to a human esophageal squamous cell carcinoma cell line (KYSE-510) by induction of G2/M arrest and apoptosis. Toxicol In Vitro 23: 797-807, 2009.
29. Mu JJ, Zeng YY, Huang XY, Zhao XH and Song B: Effects of Kaempferol on activation, proliferation and cell cycle of mouse $T$ lymphocytes in vitro. Xi Bao Yu Fen Zi Mian Yi Xue Za Zhi 25: 1106-1108, 2009 (In Chinese).

30. Eto $\mathrm{M}$ and Naito S: Molecular targeting therapy for renal cell carcinoma. Int J Clin Oncol 11: 209-213, 2006.

31. Staehler M, Rohrmann K, Haseke N, Stief CG and Siebels M: Targeted agents for the treatment of advanced renal cell carcinoma. Curr Drug Targets 6: 835-846, 2005.

32. Zhang LJ, Chen S, Wu P, et al: Inhibition of MEK blocks GRP78 up-regulation and enhances apoptosis induced by ER stress in gastric cancer cells. Cancer Lett 274: 40-46, 2009.

33. Oda K, Matsuoka Y, Funahashi A and Kitano H: A comprehensive pathway map of epidermal growth factor receptor signaling. Mol Syst Biol 1: 2005.0010, 2005. 